\title{
Land-use patterns and their implication on malaria transmission in Kilosa District, Tanzania
}

\author{
Phillipo Paul $^{1 *}$ D, Richard Y. M. Kangalawe ${ }^{1}$ and Leonard E. G. Mboera ${ }^{2}$
}

\begin{abstract}
Background: Understanding of the land use and malaria transmission among farming communities in Tanzania is of great significance. Water resource development projects, deforestation, wetland cultivation, and land use changes for agricultural purposes all expand habitats for malaria-carrying mosquitoes. The main objective of this study was to assess land use patterns and their implication on malaria transmission in two villages in Kilosa District, Tanzania.

Methods: Multiple research methods were used for data collection, including household interviews using a structured questionnaire; key informant interviews; transect walks and direct field observations. A larval search was conducted using the dipper standard method whereby mosquito larvae and pupae were identified to genus level. Data analysis was undertaken using the Stata software version 10 and descriptive statistics were used.

Results: A total of 211 diverse mosquito breeding habitats were surveyed during this study. The mosquito breeding sites ranged from small areas such as hoof prints and coconut shells to large ones such as swamps created through anthropogenic activities. The relationships between land use patterns and malaria transmission were statistically insignificant, indicating that malaria transmission in Kilosa could possibly be due to other human activities, including seasonal movement to distant farms during farming seasons. Communities were knowledgeable about malaria preventive measures such as the use of mosquito nets. While knowledge that links mosquitoes and malaria was relatively high among respondents, knowledge related to mosquito ecology and breeding sites was generally low.

Conclusion: Although analysis of land use patterns did not show statistical significance in the study area, agricultural activities, brick making and settlement seem to be highly linked to malaria transmission. The association of land use patterns and malaria transmission is well observed in habitats created that harbour mosquitoes, and evidenced by presence of immature Anopheles mosquito larvae. Lack of knowledge of the epidemiology of transmission by the inhabitants is a major issue. Although it might be difficult to change land use patterns, as they are driven by economic necessity, future reduction of spread, through better education, is something that could be modified. In addition, more detailed studies are recommended to further confirm the linkages between land use/ cover changes and malaria transmission in the study area.
\end{abstract}

Keywords: Agriculture, Land use patterns, Malaria transmission, Tanzania

\footnotetext{
* Correspondence: dindaiphilly@gmail.com

1 Institute of Resource Assessment, University of Dar es Salaam, P.O. Box

35097, Dar es Salaam, Tanzania

Full list of author information is available at the end of the article
}

(c) The Author(s). 2018 Open Access This article is distributed under the terms of the Creative Commons Attribution 4.0 International License (http://creativecommons.org/licenses/by/4.0/), which permits unrestricted use, distribution, and reproduction in any medium, provided you give appropriate credit to the original author(s) and the source, provide a link to the Creative Commons license, and indicate if changes were made. The Creative Commons Public Domain Dedication waiver (http://creativecommons.org/publicdomain/zero/1.0/) applies to the data made available in this article, unless otherwise stated. 


\section{Background}

Globally there is a significant correlation between land use and malaria transmission. Water resource development, deforestation, wetland cultivation, crop cover and land use changes for agricultural purposes in the highlands, wetland cultivation and increase in urban agriculture all expand habitats for malaria carrying mosquitoes [1-6], resulting in the upsurge of malaria transmission in various places.

Various scholars hold that in Africa malaria is predominantly a rural disease and it has been observed that Anopheles mosquito breeding decreases with urbanization $[2,5,6]$. However, in various cities in Africa with poor environmental management and peri-urban agriculture including fish ponds are providing favourable habitats for mosquitoes $[2,6,7]$ thereby enhancing malaria transmission due to higher adult Anopheles densities with more malaria episodes than in non-agricultural locations $[5,8]$.

In the rural areas, deforestation is one of the most potent factors in emerging and re-emerging infectious diseases [9]. Deforestation is driven by a wide variety of human activities, including agricultural development, logging, transmigration programmes, road construction, mining, and hydropower development [10]. These processes alter the various elements of local ecosystems such as microclimate, soil, and aquatic conditions, and most significantly, the ecology of local flora and fauna, including human disease vectors like Anopheles mosquitoes. As reported by Yasuoka and Levins [9], mosquitoes are very sensitive to environmental changes. Deforestation and land transformations have influence on vector Anopheles, especially larval and adult survivorship, reproduction, and vector capacity, leading to a prolonged seasonal malaria transmission [11, 12]. For example, the re-emergence of malaria in the highlands of Western Kenya has been greatly blamed on the clearing of the forests for the development of tea estates [13]. Similar observations have been reported in the highlands of Tanzania in Muheza, Mpwapwa, Iringa, Rungwe and Muleba districts [14], the Rukungiri and Kabale districts of Southwest Uganda, and in the Rwanda highlands [1519].

The effects of deforestation on malaria transmission may be spatially variable and highly dependent on vector distribution [20]. This is because the vector species could adapt to different types of land cover and therefore could make the effect on malaria transmission regionally distinctive and even locally specific. These scholars reported, for instance, that the clearing of forest lands for rice cultivation may provide more favourable conditions for the Anopheles gambiae or An. albitarsis but can reduce transmission in areas where $A n$. dirus is the main vector. However, in situations where the forest clearing leads to tree crop plantations, the An. dirus may find suitable breeding conditions in the plantations similar to the vector's natural habitats [20].

Reclamation of wetlands for cultivation in Africa has also been associated with increased vector abundance and malaria transmission [21]. Minakawa [22] reported that extensive cultivation of the valley bottoms across East Africa as a result of rapid population and demand for more food has changed the local ecology. These wetlands were covered with natural papyrus, which limits the breeding of $A n$. gambiae due to the dense vegetation and the oily layer. The elimination of the papyrus and the reclamation of the swamps have led to increase in temperatures, promoting the breeding and survival of the mosquitoes and thereby increasing malaria transmission in the affected areas $[15,16]$. The Kilombero Valley in Tanzania is one of the areas described as highly malaria-endemic tropical wetland dominated by subsistence agriculture [23].

Changes in land use/cover patterns have also been associated with the emergence of highland malaria. Traditionally most of tropical highlands had little or no malaria [24-28]. This situation has changed with several highland areas in the tropics experiencing major malaria epidemics in the last 30 years $[14,18]$. The increasing prevalence of malaria in the highlands of Africa, especially in Eastern Africa, has to a large extent been attributed to agricultural practices that have resulted in changes in rainfall patterns, temperature, and vegetation and ecology that is often accompanied by a massive increase in population in areas of unstable endemic transmission [17]. This study, therefore, assessed the changes in land use patterns and their implication on malaria transmission in Kilosa district of central Tanzania.

\section{Methods}

\section{The study area}

This study was conducted in Kimamba "A" and "B" villages in Kimamba ward (Fig. 1) in Kilosa District in central Tanzania. The study villages had a total population of 10,562 persons [29]. The district is located in a tropical semiarid environment with a bimodal type of rainfall and an average temperature of $25{ }^{\circ} \mathrm{C}$ [30]. The short rains are received from October through December and the long rains from mid-February through May [30-33]. The climatic condition of the district varies depending on the agro-ecological zones, with the highest parts of the district at $2200 \mathrm{~m}$ above sea level getting annual rainfall ranging from 1000 to $1600 \mathrm{~mm}$. This area is characterized by moderately fertile well drained sandy clay loam soils. The central and southern parts experience an average rainfall of $800-1400 \mathrm{~mm}$ with poorly drained black clays and loamy soils. The dominant land use is agriculture, where maize, paddy, sisal, sugarcane and vegetables are cultivated. The selected study villages 


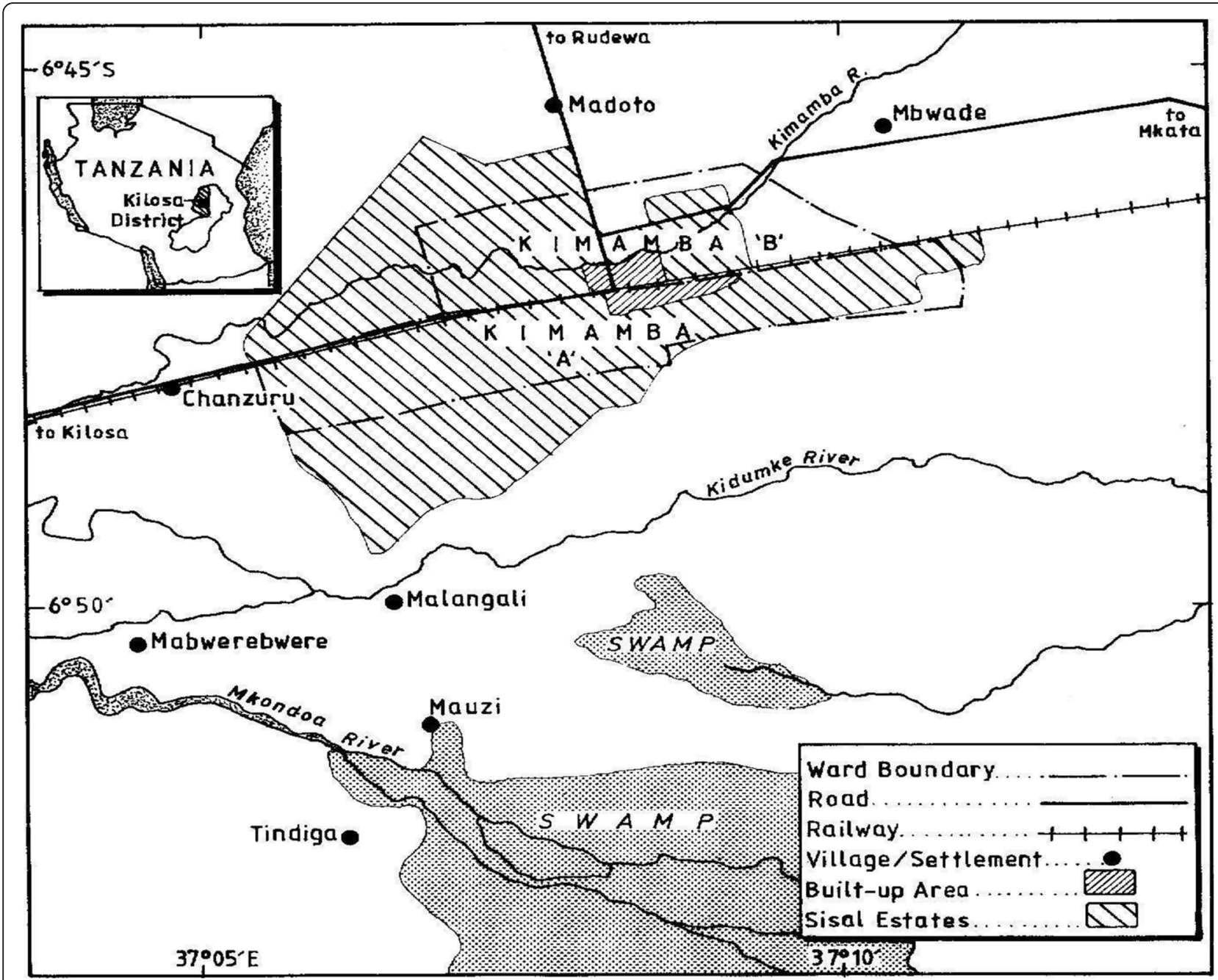

Fig. 1 Map of Kimamba villages

were involved in a larger study titled Integrated Research Partnership for Malaria through an Ecohealth Approach in East Africa.

\section{Research methods}

Multiple research methods were used for data collection, including household interviews using a structured questionnaire; key informant interviews; transect walks and direct field observations. Household interviews involved

Table 1 Age of respondents expressed in percent

\begin{tabular}{|c|c|c|c|c|c|c|}
\hline \multirow{2}{*}{$\begin{array}{l}\text { Age } \\
\text { group } \\
\text { (years) }\end{array}$} & \multicolumn{2}{|c|}{ Kimamba A } & \multicolumn{2}{|c|}{ Kimamba B } & \multicolumn{2}{|l|}{ Total } \\
\hline & Male & Female & Male & Female & Male & Female \\
\hline 18-35 & 21.3 & 38.4 & 18.5 & 22.5 & 19.9 & 30.5 \\
\hline $36-55$ & 11.2 & 12.9 & 12.1 & 25.2 & 11.7 & 19.1 \\
\hline $56+$ & 6.4 & 9.8 & 10.7 & 11 & 8.6 & 10.4 \\
\hline Total & 38.9 & 61.1 & 41.3 & 58.7 & 40.1 & 59.9 \\
\hline
\end{tabular}

a total sample of 399 households were selected using a simple random sampling technique and representing $10 \%$ of households in the study area. The sample comprised of 202 and 197 households in Kimamba "A" and "B" village respectively. The survey questionnaire covered various aspects related to types of land uses and patterns related to malaria transmission, diversities of mosquito breeding sites and control methods employed by the inhabitants. The questionnaire also solicited information on household demographic characteristics, land use information including crop production and animal husbandry, household livelihood and anthropogenic activities associated with malaria transmission, including people's knowledge, perceptions, and behaviours in relation to malaria transmission and control.

Key informants included various district officials (medical officer, planning officer, lands officer, forest officer, education officer, community development officer, executive officer and water engineer), village leaders and village natural 
Table 2 Education level of respondents expressed in percent

\begin{tabular}{|c|c|c|c|c|c|c|}
\hline \multirow[t]{2}{*}{ Level of education } & \multicolumn{2}{|c|}{ Kimamba A } & \multicolumn{2}{|c|}{ Kimamba B } & \multicolumn{2}{|l|}{ Total } \\
\hline & Men & Women & Men & Women & Male & Female \\
\hline None & 9.5 & 27.3 & 5.5 & 22.3 & 7.5 & 24.8 \\
\hline Primary & 15.9 & 41.8 & 17.2 & 50.0 & 16.6 & 45.9 \\
\hline Secondary & 1.0 & 4.5 & 1.5 & 2.5 & 1.3 & 3.5 \\
\hline Post-secondary education & 0 & 0 & 1.0 & 0 & 0.5 & 0 \\
\hline Total & 26.4 & 73.6 & 25.2 & 74.8 & 25.8 & 74.2 \\
\hline
\end{tabular}

resources committees. The interviews focused on a wide range of information such as types of land use and natural resources management practices in relation to malaria transmission. Field observations involved transect walks that were undertaken following in-depth discussions with key informants. These transect walks enabled general observation of the land use patterns, vegetation types and distribution, farming methods and mosquito breeding sites.

Mosquito breeding sites were sampled longitudinally using a standard mosquito dipper ${ }^{1}$ [34-36]. The dipping was very carefully made to avoid casting shadow in the habitat as larvae are very sensitive and would dive to the bottom once the shadow is cast on the water. The dipper was lowered gently in an angle of $45^{\circ}$ just below the surface so that water flows in together with any larvae that might be present. A total of 211 mosquito habitats were observed. From each habitat a maximum of 6-10 dips were made and sampled larvae were identified based on morphological characteristics, classified into genus level, that is, Anopheles and Culicines [37]. The information obtained here brought insight on the presence of immature mosquitoes in the sites. The investigation on the presence of mosquito breeding site aimed at establishing availability of immature anopheles in relation to location of households and to examine the frequency of contact between mosquitoes and humans.

\section{Data analysis}

Qualitative data from various sources were examined and analysed based on their content while quantitative data were coded and entered in a computer where the

Table 3 Major economic activities of the respondents expressed in percent

\begin{tabular}{llll}
\hline Occupation & Kimamba A & Kimamba B & Average \\
\hline Crop cultivation & 94.3 & 87.8 & 91.1 \\
Petty trade/Business & 2.4 & 5.3 & 3.9 \\
Employees & 0 & 2.7 & 1.4 \\
Pastoralism & 0.5 & 0 & 0.3 \\
Mixed farming & 0 & 0.5 & 0.3 \\
Others & 2.8 & 3.7 & 3.3 \\
Total & 100 & 100 & 100 \\
\hline
\end{tabular}

STATA software version 10 was used for analysis. Descriptive statistics were run to obtain frequencies, proportions and cross-tabulations. Chi-square test was conducted to establish the strength of relationships between the variables under study. Cross-tabulation allowed a comparison of different study parameters. Tables and graphs were used to present different variables.

\section{Results}

Socio-demographic characteristics of the respondents The ages of a large proportion (50.4\%) of the respondents ranged between 18 and 35 years (Table 1 ). The age between 36 and 55 years comprised of $11.7 \%$ male and $19.1 \%$ female respondents, while those above 55 years constituted of $8.6 \%$ males and $10.4 \%$ females. The age distribution is a reflection of the variation in the experiences regarding land use patterns, malaria transmissions and control. However, the relationship between age group and factors influencing presence of mosquitoes within homesteads was insignificant.

Majority of the inhabitants $(62.5 \%)$ attained primary education (16.6\% males and $45.9 \%$ females), while about one-third $(32.3 \%)$ of the respondents never went to school (7.5\% males; $24.8 \%$ females). Only 4.8 and $0.5 \%$ of respondents attended secondary and post-secondary education, respectively (Table 2). Although more educated communities are expected to have better understanding of the modes of malaria transmission and prevention, the analysis of the relationship between education level and malaria knowledge was statistically insignificant possibly because of the generally low knowledge of mosquito ecology and breeding habitats as indicated by respondents in this study.

The findings showed that 91.1 and $3.9 \%$ of communities in Kimamba depended largely on crop cultivation and small businesses respectively (Table 3 ). The major crops grown in the area included maize, paddy, beans, cassava, sweet potatoes, cotton, sunflower, sesame and sisal. Other occupations such as employees, pastoralism and mixed farming were reported by only small proportions of respondents. About 3.3\% reported to be involved in small businesses activities such as bicycle mechanic, making cook stoves, carpentry and food vending. This diversity of activities has a meaning to the local 


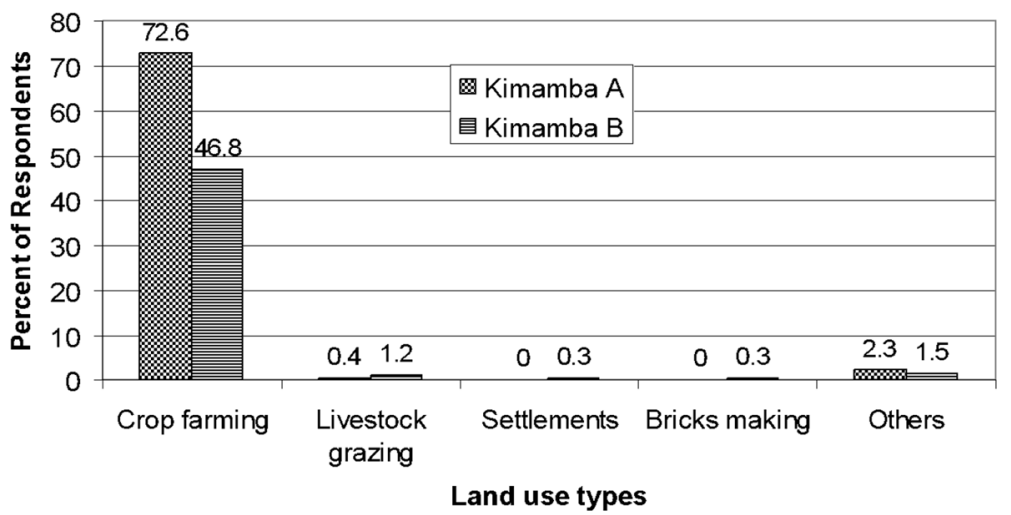

Fig. 2 Main land uses in Kimamba Villages

economies and livelihoods as it provides households with some extra income and enhances livelihood security.

Agricultural practices such as irrigation of vegetable gardens, maize and rice farms provided suitable breeding grounds for mosquitoes. However, it was found that farmers' knowledge about malaria and agricultural practices which favour the breeding of mosquitoes was low.

\section{Land use patterns associated with malaria transmission}

Major land use types found in Kimamba included settlement, crop farming, brick making and livestock grazing (Fig. 2). Crop farming was the main economic activity in Kimamba. Majority (91\%) of the respondents reported to be engaged in crop production. The major food crops grown were rice, maize, beans, cassava and plantains while the major cash crop was sisal. However, rice, maize and beans production was both for food and cash. Kimamba A had the highest percentage of people engaged in crop farming as compared to Kimamba B. Only a few $(0.3 \%)$ of respondents reported to be engaged in livestock keeping, which includes cattle, goats and sheep. The findings of this study compare well with the district, regional and national statistics that indicate that majority of Tanzanians (over $80 \%$ ) are employed in the agricultural sector [38].
The large part of land in Kimamba villages is still under sisal estates (Fig. 1). The inhabitants of Kimamba and the nearby villages were and some are still employees and labourers of the sisal estates. The inhabitants are only left with very small land for cultivation and other few areas left for settlement and house construction. It was reported by almost all respondents that for them to cultivate they have to either rent a piece of land from the investors for $2000 /=$ per acre or purchase land in nearby villages located between 4 and $18 \mathrm{~km}$ from the respondents' homesteads, which takes 1-4 h walk. As they go to their farms most farmers prefer to stay overnight rather than returning home every day. The mentioned reasons of staying overnight included reducing travel times to and from the field as reported by $16 \%$ of respondents, protecting crops from grazing domestic animals $(10 \%)$, and protecting crops from wild animals (11\%). Other reasons given included farm preparation (7\%), planting (8\%), weeding (13\%) and during harvesting season $(51 \%)$ when much time is needed in the field. It is during such times when they are bitten by mosquitoes.

The study finding indicated that $64.9 \%$ of respondents suffered from malaria during the long rainy season (April to June). This is the season when people spend most of

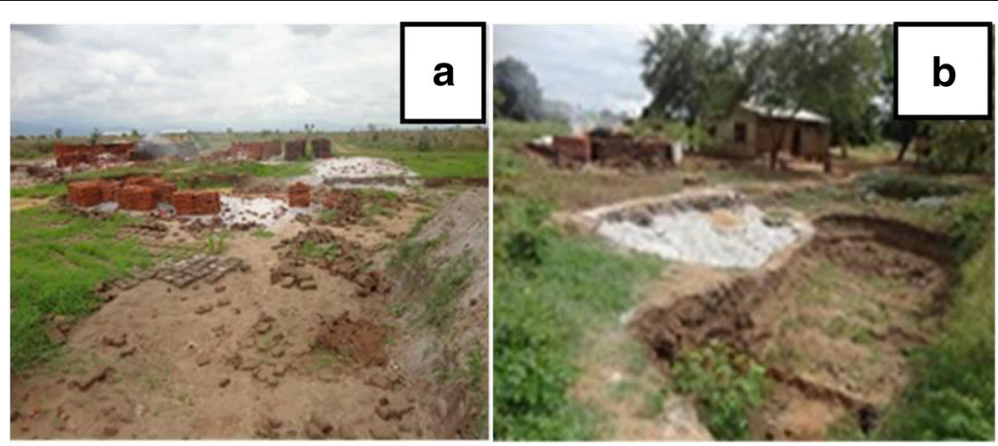

Fig. 3 Bricks making sites (a) in a public place and (b) near the homestead 


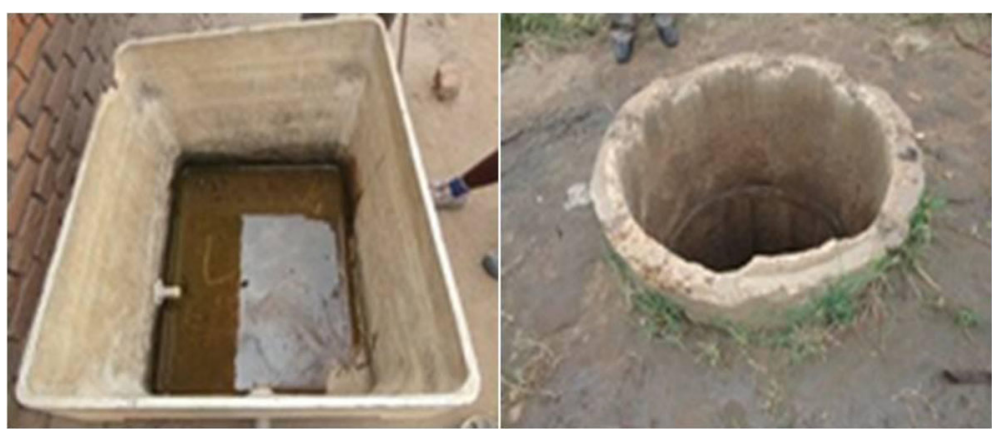

Fig. 4 Water container (left) and an open well (right)

their time in their farms by temporarily shifting from their houses to farm shelters. However, about $78 \%$ of respondents reported to take with them mosquito nets to use while they are in their farm shelters to protect themselves from mosquito bites. The relationship between use of mosquito nets and its effectiveness in preventing malaria was not significant at $5 \%(\mathrm{p}>0.05)$. This was possibly due to the fact that, the mosquito nets were used only for a very short time (during sleeping), while most of the time they are exposed to mosquito bites. Moreover, the poorly built thatch grasses shelters in use have holes and uncovered windows allowing mosquito entry. Other factors include inconsistency of mosquito net use among those who own nets. It was observed that use of nets was interrupted by temporary, periodic or infrequent conditions, which inhibited net use even among regular net users. These conditions included night work, attending late-night social events, disruption of usual sleeping arrangements, net unavailability due to washing or dirtiness, extreme fatigue or forgetfulness [39].

\section{Brick making and malaria transmissions}

The study found that these villages had many sites used for brick making and some of them were located around homesteads (Fig. 3). Inhabitants reported to make bricks mostly during the dry season and is normally for business purposes and own house construction. The brick making pits have also been found to increase the outbreak of malaria in highlands of Kenya [40]. Despite many people being involved in brick making, only $0.3 \%$ of respondents in the present study knew the close relationship between malaria and brick making.

Table 4 Diversity of mosquito breeding grounds in Kimamba villages

\begin{tabular}{|c|c|c|c|c|c|c|c|}
\hline \multirow[t]{2}{*}{ Habitat type } & \multicolumn{2}{|c|}{ Kimamba "A" } & \multicolumn{3}{|c|}{ Kimamba "B" } & \multicolumn{2}{|l|}{ Total } \\
\hline & Posta & Uhindini & Mkwajuni & Sikutali & Sokomsuya & Number & $\%$ \\
\hline Water pools & 10 & 5 & 21 & 25 & 3 & 64 & 30 \\
\hline Wells & 1 & 2 & 5 & 14 & 2 & 24 & 11 \\
\hline Broken pots & 7 & 0 & 8 & 7 & 0 & 22 & 10.4 \\
\hline Hoof prints & 0 & 14 & 0 & 8 & 0 & 22 & 10.4 \\
\hline Tins & 5 & 2 & 8 & 4 & 0 & 19 & 10 \\
\hline Coconut shells & 0 & 0 & 6 & 11 & 1 & 18 & 8.1 \\
\hline Ditches & 6 & 3 & 1 & 3 & 0 & 13 & 6 \\
\hline Broken buckets & 0 & 2 & 2 & 5 & 0 & 9 & 3.3 \\
\hline Tyre marks & 2 & 0 & 0 & 2 & 0 & 4 & 1.9 \\
\hline Concrete holes & 1 & 1 & 0 & 2 & 0 & 4 & 1.9 \\
\hline Broken Drums & 0 & 1 & 2 & 2 & 0 & 5 & 2 \\
\hline Old Tyres & 1 & 1 & 0 & 0 & 0 & 2 & 1 \\
\hline Banana leaves & 2 & 0 & 0 & 0 & 0 & 2 & 1 \\
\hline Swamps & 1 & 0 & 0 & 0 & 0 & 1 & 1 \\
\hline Streams & 1 & 0 & 0 & 0 & 0 & 1 & 1 \\
\hline Water holes & 0 & 1 & 0 & 0 & 0 & 1 & 1 \\
\hline Total & 37 & 32 & 53 & 83 & 6 & 211 & 100 \\
\hline
\end{tabular}




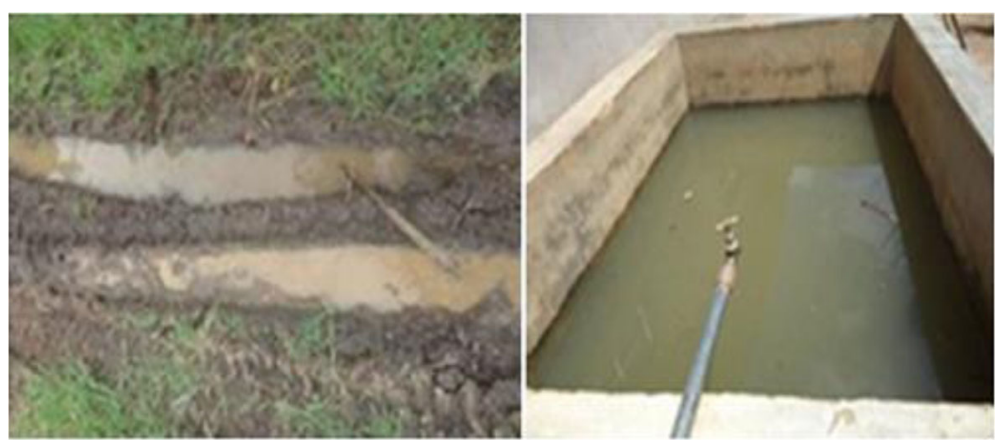

Fig. 5 Tyre marks (left) and water tank around homesteads (right)

Diversity of mosquito breeding sites in Kimamba village A total of 211 mosquito habitats (sites) were found around the homesteads (cf. Figs. 4 and 5). These habitats were grouped as small which included hoof prints, coconut shells, tins, broken pots, buckets and tyre marks (Fig. 5); medium habitats included ditches, concrete holes, wells, water tanks, water pools, broken drums streams; and the large habitats were swamps. The findings indicated that $30 \%$ of mosquito habitats observed were small, medium water pools (Table 4). Majority of these water pools were due to the brick making activities. When asked what were the main agricultural practices associated with malaria transmissions, most respondents mentioned vegetable gardening, maize and rice cultivation, both rain fed and irrigated.

Mosquito breeding habitats ranged from as small as hoof prints, coconut shells to the large ones such as swamps. Majority (95\%) of the observed habitats represent mosquito breeding sites that were man-made. Most of the man-made habitats were linked to livelihood activities such as farming and house construction. The status of the observed mosquito habitats was analyzed and grouped as presented in the Table 5.

Mosquito larval search was conducted in all breeding sites identified in the study area. Findings showed that $28 \%$ out of $61.1 \%$ of the total wet mosquito breeding sites identified had immature mosquitoes, while 10 and $8 \%$ of these were identified to be Anophelines and Culicines, respectively. The abundance of immature mosquitoes for the two species was associated with ecological factors such as rainfall and breeding habitats.

\section{Discussion}

While the general knowledge that link mosquito and malaria among farming communities in Kilosa district was reported to be high, there is very low knowledge on mosquito ecology and breeding sites among the inhabitants. Such ignorance of the ecology of malaria vector in the study area is likely to increase the mosquito productivity by creating more breeding sites. Agriculture was mostly reported by the respondents as only the reasons for increased malaria intensity in Kimamba villages, because it supports breeding of mosquitoes that carry the malaria parasites. These results are supported by various works done in Tanzania [41-44]. Malaria is a particular problem in agricultural areas, as land use practices implemented often result in increased presence of breeding sites [6, 45]. The influence of agricultural systems on health is particularly notable via the intermediary process of land use change. Agricultural production systems including farming practices, location of farms, and farming technologies could lead to land use change that create suitable ecological and climatic conditions for the breeding and survival of the Anopheline mosquitoes, which transmit the malaria [6].

Table 5 Percent response on the status of mosquito breeding sites in Kimamba village

\begin{tabular}{|c|c|c|c|c|c|c|c|}
\hline \multirow[t]{2}{*}{ Villages } & \multirow[t]{2}{*}{ Sub-village } & \multicolumn{2}{|c|}{ Water status } & \multicolumn{2}{|l|}{ Origin } & \multicolumn{2}{|c|}{ Associated livelihoods } \\
\hline & & Water & Dry & Man-made & Natural & Farming & Constructions \\
\hline \multirow[t]{2}{*}{ Kimamba "A" } & Posta & 9.0 & 10.4 & 18.5 & 0.9 & 4.7 & 14.7 \\
\hline & Uhindini & 7.1 & 8.1 & 12.3 & 2.8 & 1.9 & 13.3 \\
\hline \multirow[t]{4}{*}{ Kimamba "B" } & Mkwajuni & 17.1 & 7.1 & 24.2 & 0 & 0.5 & 23.7 \\
\hline & Sikutali & 26.5 & 12.8 & 38.4 & 0.9 & 14.7 & 24.6 \\
\hline & Sokomsuya & 1.4 & 0.5 & 1.9 & 0 & 0.5 & 1.4 \\
\hline & Total & 61.1 & 38.9 & 95.3 & 4.7 & 22.3 & 77.7 \\
\hline
\end{tabular}


Despite of the fact that brick making and settlement were highly practiced in Kimamba, the respondents did not directly link them with an increase of malaria productivity. The study by Carlson [40] in western Kenya revealed that brick-makers make bricks predominantly during the dry-season. The whole process of brick making leaves behind temporary and permanent pools which store water especially during rainy seasons. During long rains the number of immature mosquitoes increases while during dry season decreases due to the availability of more breeding sites in the former than latter period. These results conform to the findings from other studies on the population dynamics of the mosquitoes.

Majority of the breeding sites found in this study were created by human. The diversity of breeding sites suggests the possibilities of emergence and re-emergence of malaria as they provide conducive environment that favour mosquito survival. It is common that mosquitoes breed and multiply easily in the temporary and permanent habitats occupied by water with favourable temperature $[24,46]$. This study found that majority of the mosquito breeding habitats were located within the homesteads. Presence of these habitats around homesteads increased the contact between humans and mosquitoes hence enhanced malaria transmissions.

Most of the Kimamba inhabitants are involved in temporal and spatial movements, including circulation and migration. Circulation encompasses a variety of movements, usually short-term and cyclical and involving no longstanding change of residence while migration involves a permanent change of residence [47]. It was reported by key informants and households interviewed during the present study that there were seasonal movements of people in the study area. During the farming season people move from various parts of Tanzania to Kimamba where they rent houses and land for farming purposes. Movements from Kimamba villages to their distant farms were also reported. The farming season begins during the short rainfall of October to December. It is quite possible that some people come to this area already infected by malaria or carrying the parasite. The spatial movement to and from malaria areas are of epidemiologic importance. Pim and Lisbeth [47] reported for instance that people who move can be categorized as either active transmitters or passive acquirers. Active transmitters harbour the parasite and transmit the disease when they move to areas of low or sporadic transmission. Passive acquirers are exposed to the disease through movement from one environment to another; they may have low-level of immunity or may be non-immune, which increases their risk for malaria. Similar experiences were reported for highland areas of southern Tanzania by Kangalawe [19].

During farm activities people shift temporarily from their traditional homesteads to distant farms. Thus, it is possible that during this shift people transmit malaria from the farms where they mostly contract the disease to their permanent areas [47]. The University of Richmond [48] maintained that humans become vectors capable of transmission when they become active transmitters. According to Pim and Lisbeth [47], active transmitters harbour the parasite and transmit the malaria when they move to areas of low or sporadic transmission. Passive acquirers become active transmitters once they are infected because humans can transmit malaria gametocytes to uninfected mosquitoes or mosquitoes infected with asexual (non-infective) stage of Plasmodium development [49].

\section{Conclusion}

This study shows that changes in land use patterns are associated with malaria transmission as demonstrated by presence of diverse habitats for mosquitoes in the land units used for various purposes. Although the analysis of land use patterns did not show statistical significance in the study area, agricultural activities, brick making and settlement seem to be highly linked to the malaria transmission. The association of land use patterns and malaria transmission is well observed in habitats created that harbour mosquitoes, and evidenced by presence of immature of Anopheles and Culicines mosquito larvae. The presence of diverse habitats in various land use patters suggests that controlling malaria transmission in those areas would need multi-stakeholder, multidisciplinary and integrated approaches. Lack of knowledge of the epidemiology of transmission by the inhabitants is a major issue. Although it might be difficult to change land use patterns, as they are driven by economic necessity, future reduction of spread, through better education, is something that could be modified. In addition, more detailed studies are recommended to further confirm the linkages between land use/cover changes and malaria transmission in the study area.

\section{Endnotes}

${ }^{1}$ The standard mosquito dipper is the most commonly used tool for collecting mosquito larvae and pupae from a wide variety of habitats. Dippers vary in size and shape but are often white to facilitate detection of larvae. Local availability often dictates the size of dipper used, which unfortunately is not always clearly recorded with the results of surveys.

\section{Abbreviations}

FAO: Food and Agriculture Organization; IPMA: Integrated Research Partnership for Malaria - Eco-Health Approach; NIMR: National Institute for Medical Research; URT: United Republic of Tanzania; $X^{2}$ : Chi-Square

\section{Acknowledgements}

This paper is based on a research project undertaken as part of Master of Science in Natural Resources Assessment and Management dissertation work at the University of Dar es Salaam by the first author. Fieldwork for this study 
was supported by the National Institute for Medical Research (NIMR) through the Integrated Research Partnership for Malaria - Eco-Health Approach in East Africa (IPMA) project for which the authors are grateful.

\section{Availability of data and materials}

Please contact author for data requests.

\section{Authors' contributions}

PP participated in the development of the research proposal, design of the study, data collection in the field, data analysis and manuscript writing. RYMK and LEGM supervised the research and participated in the research design, review and editing of the manuscript. All authors read and approved the final manuscript.

\section{Ethics approval and consent to participate}

This study received an ethical clearance from the Medical Research Coordinating Committee of the National Institute for Medical Research Ref. No. NIMR/HQ/R.8a/Nol IX/1131. The objectives, methods and benefits of the study were explained to villagers through their village leaders. Before any larval sampling was initiated, verbal consent to access compounds and farms was obtained from both administrative officials and residents during local village meetings. All interviewees provided informed verbal consent before the interview.

\section{Competing interests}

The authors declare that they have no competing interests.

\section{Publisher's Note}

Springer Nature remains neutral with regard to jurisdictional claims in published maps and institutional affiliations.

\section{Author details}

${ }^{1}$ Institute of Resource Assessment, University of Dar es Salaam, P.O. Box 35097, Dar es Salaam, Tanzania. ${ }^{2}$ National Institute for Medical Research, P.O. Box 9653, Dar es Salaam, Tanzania.

\section{Received: 24 March 2017 Accepted: 6 June 2018}

\section{Published online: 20 June 2018}

\section{References}

1. Lindblade K, Walker E, Onapa A, Katungu J, Wilson M. Land use change alters malaria transmission parameters by modifying temperature in a highland of Uganda. journal of Trop Med Int Health. 2000;5(4):77-85.

2. Robert V, Macintyre K, Keating J, Trape J, Duchemin J, Warren M, Beier J. Malaria transmission in urban sub-Saharan Africa. Journal of American Tropical Medicine and Hygiene. 2003;68(2):169-76.

3. Patz J, Daszak P, Tabor G, Aguire A, Pearl M, Epstein J, Wolfe N. Unhealthy landscapes: policy recommendations on land use change and infectious disease emergency. Environ Health Perspect. 2004;112(10):1092-998.

4. Vanwambeke, S., Lambin, E., Eichborn, M., Flasse, S., Harbach, R., Askam, L., Somboon, P., Van beers, S., Birgit, H., Van Bethem, B., Walton, C. and Butlin, R. (2007), Impact of land use change on dengue and malaria in northern Thailand, Thailand.

5. Klinkenberg E, McCall P, Hastings I, Wilson M, Amerasinghe F, Donnelly M. Malaria and irrigated crops, Accra, Ghana. Journal of Emerging Infectious Diseases. 2005;11(8):1290-2.

6. Okyere K, Asante F, Tarekegn J, Andam K. "The Linkages between Agriculture and Malaria. Issues for Policy, Research, and Capacity Strengthening", IFPRI Discussion Paper 00861. International Food Policy Research Institute, (v)+31pp; 2009. https://pdfs.semanticscholar.org/9d81/ 58dc5dc70aa90fac19627fb2b303fb286fbc.pdf.

7. Afrane $Y$. Does irrigated urban agriculture influence the transmission of malaria in the city of Kumasi, Ghana. Journal of Acta Tropica. 2003:89(2): 125-34.

8. Matthys B, Vaunatsou P, Raso G, Tschannen A, Becket G, Gosoniu L, Cisse G, Tanner M, N'Goran E. Urban farming and malaria 85 risk factors in a medium-sized town in cote d'Ivoire. Journal of American Tropical Medicine and Hygiene. 2006;75(6):1223-31.

9. Yasuoka J, Levins R. Impact of deforestation and agricultural development on Anopheline ecology and malaria epidemiology. Journal of America Tropical Medicine and Hygiene. 2007;76(3):450-60.
10. FAO. Satellite technology yields new forest loss estimates. 2011. http:// www.fao.org/news/story/en/item/95180/icode/. Accessed 18 June 2018.

11. Kondrashin A, Jung R, Akiyama J. Ecological aspects of forest malaria in Southeast Asia. In: Sharma VP, Kondrashin AV, editors. Forest malaria in Southeast Asia. New Delhi: WHO/Medical Research Council; 1991.

12. Pattanayak K, Yasuoka J. Deforestation and malaria: revisiting the human ecology perspective. In: Colfer CJP, editor. People, Health, and Forests: a global interdisciplinary overview; 2006. Earthscan.

13. Malakooti M, Biomndo K, Shanks G. Re-emergence of epidemic malaria in the highlands of western Kenya. Journal of emerging infectious disease. 1998;4(4):335-45.

14. Mboera LEG. Environmental and socio-economic determinants of malaria epidemics in the highlands of Tanzania. Tanzania Health Research Bulletin. 2004;6:11-7

15. Kanzaria, H. (2003), Highland malaria in East Africa with a focus on land use Centre of Environmental Studies, Brown University.

16. Githeko A, Munga S, Afrane Y, Guiyun Y. Land use changes and micro climate change: lessons for highland malaria and climate change. Nairobi: Kenya Medical Research Institute (KEMRI); 2003.

17. Reiter P. Climate change and highland malaria in the tropics. Abstract of presentation to avoiding dangerous climate change, international symposium on the stabilization of greenhouse gas concentration. Exeter: Hadley centre, Met officer; 2004. 1-3 February 2004

18. Yanda PZ, Kangalawe RYM, Sigalla RJ. Climatic and socio-economic influences on malaria and cholera risks in the Lake Victoria region of Tanzania. ICIFAI Journal of Environmental Economics. 2006;4(3):44-70.

19. Kangalawe RYM. Food security and health in the southern highlands of Tanzania: a multidisciplinary approach to evaluate the impact of climate change and other stress factors. African Journal of Environmental Science \& Technology. 2012;6(1):50-66.

20. Guerra C, Snow R, Hay S. A global assessment of closed forest, deforestation and malaria risk. Journal of Annals of Tropical Medicine and Parasitology. 2006;100(3):3-7

21. Sousa A, Andrade F, Félix A, Jurado V, León-Botubo A, A-A-Murillo P, GarcíaBarrón L, Morales J. Historical importance of wetlands in malaria transmission in southwest of Spain, Asociacio'n Ibe'rica de Limnolog'a, Madrid; 2009.

22. Minakawa N, Munga S, Atieli F, Mushinzimana E, Zhou G, Githeko A, Yan G. Spatial distribution of anopheline larval habitats in western Kenyan highlands: effects of land cover types and topography. Journal of American Tropical Medicine and Hygiene. 2005;73(1):157-65.

23. Hetzel M, Alba S, Frankhauser M, Mayumana I, Lengeler C, Obrist B, Nathan R. Malaria risk and access to prevention and treatment in the paddies of the Kilombero valley, Tanzania. Journal of Malaria. 2008;7:7.

24. Afrane Y, Zhou G, Lawson B, Githeko A, Yan G. Effects of microclimatic changes due to deforestation on the survivorship and reproductive fitness of Anopheles gambiae in western Kenya highlands. Journal of American Society Tropical Medical Hygiene. 2006;74(5):772-8.

25. Lindsay S, Martens J. Malaria in the African highlands: past, present and future. Journal of World Health Organ. 1998;76(1):33-45.

26. Mueller I, Namuigi P, Kundi J, Ivivi R, Tandrapah T, Bjorge S, Reeder J. Epidemic malaria in the highlands of Papua New Guinea. Journal of American Tropical Medicine and Hygiene. 2005;72(5):554-60.

27. Wandiga S, Opondo M, Kathuri J, Olago D, Apindi E, Olaka L, Githeko A Githui F, Opere A, Ogallo L, Marshall M, Downs T, Yanda Z, Kangalawe R, Sigalla R, Kabumbuli R, Kiramura E, Mugambi P, Nanyunja R, Baguma T, Achola P. Climate change induced vulnerability to malaria and cholera in the Lake Victoria region. In: A final report submitted to assessments of impacts and adaptations to climate change (AIACC), project no. AF91. Washington, DC: The International START Secretariat; 2006.

28. Wanjala C, Waitumbi J, Zhou G, Githeko A. Identification of malaria transmission and epidemic hotspots in the western Kenya highlands: its application to malaria epidemic prediction. Journal of Parasites \& Vectors. 2011;4:81.

29. United Republic of Tanzania - URT. Population and housing census. Dar es Salaam: National Bureau of Statistics Ministry of Finance; 2013.

30. Kizosa L. The Role of Local Institutions in the Management of Agro-Pastoral and Pastoral Systems: A Case Study of Mkata Plain, Kilosa District and Ngorongoro Conservation Area, Ngorongoro District, Tanzania. PhD Thesis. Morogoro: Sokoine University of Agriculture; 2007.

31. Benjaminsen T, Maganga F, Abdallah J. The Kilosa killings: political ecology of a farmer-herder conflict in Tanzania. Journal of Development and Change. 2009;40(3):427-8. 
32. United Republic of Tanzania - URT. Kilosa District Social Economic Profile. Kilosa: Kilosa District Council; 2010a.

33. United Republic of Tanzania - URT. Annual report 2010/2011. Dar es salaam: Ministry of Agriculture Food Security and Cooperatives; 2010b.

34. Service, M. Mosquito ecology. London: Applied Science Publishers; 1976

35. Michael J, Pitcairn L, Wilson T, Robert W, Eliska R. Spatial patterns of Anopheles freeborni and Culex tarsalis (Diptera: Culicidae) larvae in California Rice fields. Journal of Medical Entoniol. 1994;31(4):545-53.

36. Silver B. Mosquito ecology: field sampling methods. The Netherland: Springer Science and Business Media B.V; 2008.

37. David $\mathrm{H}$. Evaluation of the standard pint dipper as a quantitative sampling device for mosquito larvae. Journal of Entomological Society of America. 1971;64(3):537-40.

38. United Republic of Tanzania - URT. Morogoro Region Socio-economic Profile. Morogoro, Tanzania: Regional Planning Department; 2007.

39. Graves P, Ngondi J, Hwang J, Getachew A, Gebre T, Mosher A, Patterson E, Shargie E, Tadesse Z, Wolkon A, Reithinger R, Emerson P, Richards F. Factors associated with mosquito net use by individuals in households owning nets in Ethiopia. Malar J. 2011;10:2.

40. Carlson J, Byrd B, Omlin F. Field assessments in western Kenya link malaria vectors to environmentally disturbed habitats during the dry season. Journal of BMC Public Health. 2004;4(33):1471-2458.

41. Ijumba J, Lindsay S. Impact of irrigation on malaria in Africa: paddies paradox. Med Vet Entomol. 2001;15:1-11.

42. Mboera L, Makundi E, Kitua A. Uncertainty in malaria control in Tanzania: crossroads and challenges for future interventions. The American Journal of Tropical Medicine and Hygiene. 2007;77(6):112-8.

43. Mboera L, Kesheni P, Benjamin K, Susan F, Rwehumbiza T, Rwegoshora M, Elizabeth S, Shayo H. Spatio-temporal variation in malaria transmission intensity in five agro-ecosystems in Mvomero district, Tanzania. Dar es Salaam, Tanzania: National Institute for Medical Research; 2010.

44. Mboera L, Senkoro K, Rumisha S, Mayala B, Shayo E, Mlozi M. Plasmodium falciparum and helminth co-infections among schoolchildren in relation to agro-ecosystems in Mvomero District. Dar es Salaam, Tanzania: Tanzania. National Institute for Medical Research; 2011.

45. Randell H, Dickinson K, Shayo E, Mboera L, Kramer R. Environmental Management for Malaria Control: knowledge and practices in Mvomero, Tanzania. Journal of EcoHealth consortium. 2010;7(4):507-16.

46. Cohen J, Ernst K, Lindblade K, Vulule J, John C, Wilson M. Local topographic wetness indices predict household malaria risk better than land-use and land-cover in the western Kenya highlands. Malar J. 2010;9:328.

47. Pim M, Lisbeth H. Malaria on the move: human population movement and malaria transmission. Journal of Emerging Infectious Disease. 2000;6(2):103-8.

48. University of Richmond (2012). Effect of land use change on exposure to and transmissions of pathogens. Environmental studies senior seminar, University of Richmond.

49. Locroix R, Mukabana W, Gouagna L, Koella J. Malaria infection increases attractiveness of human to mosquitoes. Journal of PLOS Biology. 2005;3(9): 1590-3.

\section{Ready to submit your research? Choose BMC and benefit from:}

- fast, convenient online submission

- thorough peer review by experienced researchers in your field

- rapid publication on acceptance

- support for research data, including large and complex data types

- gold Open Access which fosters wider collaboration and increased citations - maximum visibility for your research: over $100 \mathrm{M}$ website views per year

At BMC, research is always in progress.

Learn more biomedcentral.com/submissions 